\title{
Agnia Grigas, The New Geopolitics of Natural Gas, Cambridge: Harvard University Press, 2017.
}

I.

주요한 에너지원임도 불구하고, 천연가스는 석유와 같은 영향력을 가져본 적이 없다. 석유는 지금까지 지정학적 판도를 만들어 나갔던 여러 요소 중 하나였으며 전시 군사전략과 평시 민간외교 모두에 큰 영향을 끼쳤던 품목이 었다. 이에 반해 천연가스는 장거리 운송의 어려움 등으로 인해 석유와 같은 ‘글로벌시장 품목(global commodity)’이 되지 못한 채, 생산지와 그 주변 지 역에서 소비되고 가격이 형성되는 '지역시장 품목(localized commodity)'이었 으며, 각 지역마다 상이한 시스템에 의해 가격이 형성되고 유통되었다. 하지 만 이제 상황이 변화하고 있다. 새로운 가스추출 기술, 운송 기술의 획기적 인 발전, 그리고 통합된 글로벌 천연가스 시장의 형성 등으로 인해 이제 천 연가스는 에너지원으로서 뿐만 아니라 석유가 가지고 있던 에너지 안보 및 에너지 지정학에서의 역할을 대체해 가고 있다.

아그니아 그리가스(Agnia Grigas)의 『천연가스의 새로운 지정학(The New Geopolitics of Natural Gas)』(Cambridge: Harvard University Press, 2017)는 유라시아 정치와 산업부문에 대한 개관과 함께, 북미발 '셰일혁명(Shale Revolution)'과 글로벌 가스 시장이 가져올 거대한 지정학적 변화에 대한 연 구이다. 이 책을 관통하는 주요 주제는 다음 세 가지이다. (1) 미국산 셰일가 스 생산으로 인한 천연가스 물량의 급증과 시장 유동성의 증가이다. 지금까지 유가(油價)에 연동되어 가격이 결정되고 장기거래가 주였던 관행에서 벗어나

* 재단법인 여시재 (Lee, Jeong-Ha, Solution Designer of the Future Consensus Institute Yeosijae). 
글로벌 가스 시장은 단기매매와 현물거래가 중심이 된 형태로 변모하고 있다. (2) 새롭게 발전하고 있는 액화천연가스(Liquefied Natural Gas, LNG) 관련 기술 즉 천연가스 생산기술과 해운업 등의 발전으로 인해 가스운송이 보다 경제성을 확보하게 되었다. 가스 시장은 이전의 파이프라인 운송 천연가스 (Piped Natural Gas, PNG)에서 LNG를 중심으로 급격하게 변화하고 있다. (3) 셰일혁명과 글로벌 가스 시장의 형성은 과거 주요 에너지 공급국이었던 러시 아와 가스프롬이 가지고 있던 영향력을 약화시키고 있다. 본서는 바로 이러 한 변화의 양상과 그로 인한 미국, 유럽, 러시아, 중국 등의 전략적 관계 변 화를 분석하고 있다.

II.

저자는 천연가스에 기반한 에너지 지정학을 지역별로 구분하여 분석한다. 러시아의 ‘공급(Supply)’, 유럽의 ‘의존(Dependence)', 우크라이나와 벨라루스 의 ‘통과(Transit)', 중앙아시아의 ‘소규모의 (항만시설과) 단절된 공급(Small/ Isolated Supply)' 그리고 중국과 아시아의 '수요(Demand)' 등으로 나누어 설 명하고 있다.

공급, 의존, 통과, ‘단절된 공급' 그리고 수요 등의 분석 이전에, 그리가스 는 제 1 장[“변화하는 세계 천연가스 부문(The Changing Global Gas Sector)”] 과 제2장[“미국 LNG 수출의 정치적 및 통상적 측면(The Politics and Commerce of American LNG Exports)"]에서 천연가스가 주요한 품목으로 등 장하게 된 정치적, 경제적 그리고 국제관계적 배경지식을 소개한다. 1970년 대 초반 OPEC의 석유금수조치가 어떻게 '수압파쇄법(hydraulic fracturing)',1) '수평시추(horizontal drilling)',2) '3D 탄성파탐사(3D seismic imaging)' 등의 기술 발전에 자극을 가하고 미국이 셰일가스 개발로까지 나아갔는지 그리고 셰일혁명이 현재 진행되고 있는 글로벌 천연가스 시장 형성에 어떤 영향을 주고 있는지를 서술하고 있다. 즉 미국에서의 셰일가스 생산, 글로벌 LNG 거래의 등장, 그리고 세계 각지의 가스 수송기반시설의 확충 등은 과거 석유

1) 비전통적 석유와 가스를 생산하기 위해 고압의 액체를 이용하여 광석을 파쇄하는 채광 방법.

2) 기존의 수직시추(vertical drilling)가 수직방향으로 좁은 면적의 가스층만 생산에 이 용한 것과 달리, 가스가 있는 위치까지 수직으로 관을 삽입한 후 진입 각도를 수 평으로 하여 가스를 채굴하는 기술. 
에 밀려 제한된 의미만 가지고 있던 천연가스라는 품목을 글로벌 가치사슬에 서 매우 중요한 품목으로 변화시키고 있다.

그리가스는 또한 변화하고 있는 에너지 지정학의 복잡한 양상도 서술하고 있다. 셰일혁명으로 인해 미국은 거대 에너지 소비국과 수입국에서 LNG 기 준 최대 에너지 수출국으로 변모하고 있다. 중국의 도전을 받고 있기는 하지 만 명실상부한 패권 국가 미국이 이제 에너지까지도 확보하게 되면서 기존의 지정학적 역학관계에 미치는 영향은 다대할 것이다. 2016년 이전까지도 전문 가들은 미국산 천연가스 수출이 소위 ‘아시아 프리미엄(Asian Premium)'이 존재하는 동북아시아에서나 혹은 기껏해야 지리적으로 인접한 남미지역에서 나 가능할 것으로 전망하였다. 하지만 2017년 6월 미국산 가스가 폴란드에 수출되었고, 이는 유럽에 대한 전통적 에너지 공급국인 중동지역 국가들과 러시아의 입지를 위협할 상징적 사건이었다.

제3장[“공급의 정치학: 러시아와 가스프롬(The Politics of Supply: Russia and Gazprom)"]은 PNG에 기반하고 있는 러시아의 ‘공급의 정치학’을 다루고 있다. 천연가스는 러시아 경제에서 매우 중요한 비중을 차지하고 있었고, 가 스프롬은 에너지를 공급받거나 에너지 수송로 상에 있던 국가들을 통제하고 제어하는 도구였다. 국가 경제의 상당 부분을 에너지 수출을 통해 운영하고 있는 러시아에게는, '자원의 저주'를 벗어나기 위한 경제체질 개선을 위해서 도 에너지 수출을 통한 재원 마련이 앞으로도 절실한 형편이다. 이러한 상황 에서 미국산 셰일가스로 인한 물량증가와 글로벌 천연가스 시장의 등장은 PNG에 기반하고 있던 러시아의 시장지배력과 에너지 공급국으로서의 입지 를 급격하게 약화시키고 있다. 2017년 4월 가스프롬 대표인 알렉세이 밀레르 (Alexey Miller)는 유럽에서 러시아 에너지가 차지하고 있는 영향력에 대해 언급하면서, 미국산 셰일가스를 포함한 $\mathrm{LNG}$ 는 러시아산 $\mathrm{PNG}$ 의 적수가 될 수 없으며 이는 향후에도 그러할 것이라고 득의양양하게 주장하였다. 하지만 현재 러시아가 취하고 있는 에너지 전략의 변화를 살펴보면, 러시아 또한 유 럽 시장에서의 러시아 가스 수요감소를 인식하고 있으며 이를 상쇄하고자 주 된 에너지 공급지역을 중국을 포함한 동북아시아 지역으로 변화하고자 노력 하고 있다. 소위 '신동방정책’으로 불리는 러시아의 정책도 결국 이와 일맥상 통한다고 볼 수 있다.

그리가스는 지정학적 이익을 달성하기 위한 러시아의 ‘자원 무기화’에 대 해서는 자세하게 다루고 있지는 않다. 주로 러시아와 가스프롬이 수행하였던 
경제적 활동에 초점을 맞추고 있다. 물론 가스프롬이 국영 에너지회사임을 감안하면 이러한 경제적 활동이 단순히 경제적 활동으로만 끝나지 않을 것이 라는 점은 명확하지만 말이다.

에너지를 둘러싼 지정학적 긴장은 유럽국가들의 러시아산 에너지에 대한 의존을 다루는 제 4 장[“변화된 의존의 정치학: 유럽(The Politics of Dependence Transformed: Europe)”]에서 보다 명확하게 드러난다. 오래전부터 유럽은 러 시아산 가스에 대한 의존도를 낮추고자 노력하였다. 1970-1990년대 점차 노 골화되었던 러시아의 ‘압박', 노르웨이의 가스 매장량 감소 등은 유럽의 많은 국가들이 러시아의 영향력을 약화시킬 새로운 공급처를 찾도록 만들었다. 이 후 알제리와 영국에서의 가스 개발과 카타르로부터 LNG 도입 등으로 인해, 2000 년대 초반 가스프롬은 유럽에서 $20 \%$ 가 넘는 시장지분을 상실하였다. 러 시아산 에너지의 영향력을 줄이기 위한 유럽의 기본 전략은, 화석연료의 소 비축소 및 신재생에너지 소비증가, 그리고 에너지 효율성 증가이다. 이와 함 께 '3차 에너지 패키지(Third Energy Package)'3) 등의 정책을 수행하는 것이 다. 셰일혁명과 글로벌 가스 시장의 형성이 러시아에 대한 의존을 일소하지 는 못하겠지만, 상황은 유럽에게 유리하다. 이에 더해 그리가스는 에너지를 둘러싼 지정학적 압박을 회피하기 위한 궁극의 조치로 소위 '유럽 에너지공 동체(European Energy Union)' 구상을 제시한다. 에너지공동체는 단일한 에너 지 전략, 단일한 목소리 등을 통해 유럽의 에너지 안보수준을 제고시키고 향 후 보다 강력한 협상력을 가지도록 할 것이다.

가스프롬과 유럽 국가들 간의 지정학적 긴장 관계는 특히 가스프롬과 벨라 루스와 우크라이나 간의 관계에서 보다 명확해진다. 이 문제는 '통과국(transit state)'을 논하는 제 5 장[“통과의 정치학: 우크라이나와 벨라루스(The Politics of Transit: Ukraine and Belarus)”]에서 다루고 있다. 실제로 러시아의 크림반도 합병은 1997년 우크라이나와 러시아에 체결된 러시아 흑해함대의 우크라이 나 항구사용 협정으로까지 거슬러 올라가는 문제이다. 가스프롬에 대한 7억 6,200만 달러에 달하는 우크라이나의 채무로 인해 1997년 이후 러시아는 지 상군과 항공기를 포함한 흑해함대의 모항으로 크림반도의 세바스토폴항을 사 용하기로 협정을 체결한 바가 있었다. 즉 천연가스와 관련된 지정학은 시장, 거래 플랫폼 그리고 LNG 수송과 같은 문제를 넘어서는 것이다. 크림반도 병

3) 유럽에서 활동하는 모든 기업이 생산, 판매와 공급망의 소유권을 분리하도록 규정 한 조항. 가스프롬과 같은 기업의 활동을 제한하는 효과가 있음. 
합은 천연가스를 중심으로 한 새로운 지정학이 결국은 언제든지 영토주권과 전쟁의 문제로 비화될 수 있음을 상기시킨다. 향후 해저 가스 개발과 관련된 영토분쟁이 중동지역과 아시아 지역에서 발생할 수도 있을 것이다. 천연가스 가 가져오는 새로운 지정학은 또다시 새로운 불안을 우리에게 안겨주고 있다.

본서는 주요 통과국으로 우크라이나와 벨라루스를 언급하고 있지만, 현재 터키가 가지고 있는 역할은 언급하지 않고 있다. 수많은 파이프라인 건설계 획이 중앙아시아, 남부 러시아 그리고 이란 등지에서 이루어지고 있으나, 결 국 모든 에너지 수송망은 터키를 통과하고 있다. 현재 러시아와 터키 사이의 긴밀한 관계는 기존의 에너지 생산국-소비국 간의 관계를 넘어서는 새로운 지정학적 판짜기라고 보아야 할 것이다.

제6장[“단절된 공급자의 정치학: 카프카즈와 중앙아시아(The Politics of Isolated Suppliers: The Caucasus and Central Asia)”]은 중앙아시아와 카프카 즈 지역을 다루고 있다. 이 장에서도 그리가스는 이들 지역의 자원 개발, 매 장량과 기반시설 그리고 과거와 현재 러시아와의 관계에 대해 서술하고 있 다. 한때 러시아는 유럽에 대한 천연가스 공급 물량의 일부분을 이들 지역을 통해 소화하였지만, 일단 러시아의 가스 생산량이 증가하자, 이들 지역은 러 시아뿐만 아니라 세계 가스 시장으로부터 소외된 지역이 되었다. 하지만 이 들 국가들 또한 새롭게 등장하고 있는 글로벌 가스 시장에 어떤 형태로든 참여하고자 할 것이다. 글로벌 가스 시장이 주로 $\mathrm{LNG}$ 를 중심으로 형성되고 있는 반면, 이들 국가들은 그 지리적 조건으로 인해 생산 가스를 $\mathrm{LNG}$ 형태로 직접 수출을 할 수는 없다. 대안은 PNG에 기반하여 주변국들과의 거래라는 우회적인 방법일 것이다. 이들 국가들의 필요와 중국의 에너지 수급 필요가 만나는 바로 이 지점이 새로운 지정학이 만들어질 수 있는 또 하나의 접점이 자, 제7장[“수요의 정치학: 중국과 그 외 국가들(The Politics of Demand: China and Beyond)”]의 주요 내용이다.

중국은 세계에서 가장 거대하고 빠르게 성장하고 있는 천연가스 시장이다. 중국은 동북아시아에서 미국의 일방주의에 맞서기 위한 전략적 파트너로서 그리고 에너지 공급자로서 러시아와의 관계에 주의하고 있으나, 다른 한편 에너지 도입선 다원화를 통해 러시아의 영향력을 조절하고자 한다. 중국은 러시아보다도 중앙아시아와 카프카즈 지역과의 관계에 보다 더 큰 공을 들이 고 있다. 즉 2011년 이후로 중국은 미국을 제치고 세계 최대 에너지 소비국 가가 되었으며, 엄청난 자금을 들여 중앙아시아 지역에 에너지 관련 기반시 
설 건설을 지원하였고, 더 나아가 전략적 연합을 통한 다원화된 에너지 공급 원 확보에 주력하고 있기 때문이다. 이러한 상황에서 셰일혁명과 글로벌 가 스 시장의 형성은 중국에게 보다 좋은 기회로 작용할 것이다.

III.

많은 예측불가능한 상황들이 존재하고 있기는 하지만, 미국발 셰일혁명과 글로벌 천연가스 시장의 형성으로 인해 에너지를 둘러싼 지정학적 구도가 변 화하고 있음은 분명하다. 오랫동안 러시아로부터 천연가스를 도입하던 유럽 의 경우에는 그 함의가 특히 크다. 유럽은 지난 20여년 동안 가스 도입선을 다원화하고자 하였고, 이제 미국산 LNG 도입으로 인해 이러한 문제가 드디 어 해소될 전망이다. 물론 이후에도 러시아산 가스는 그 지리적 인접성으로 인해 유럽의 에너지 소비에서 계속 주요한 역할을 맡을 것이다. 상황이 어떻 든 유럽은 가스가 필요하고 러시아는 가스를 가지고 있기 때문이다. 그러나 새로운 상황은 러시아의 준(準)독점적인 위치에 대한 위협은 분명하다. 세계 1 위의 에너지 소비국 중국도 같은 경우이다. 특히 중국은 환경문제로 인해 석탄과 석유 소비를 줄이고 가스로 에너지 소비구조를 바꾸는데 매우 적극적 이다. 에너지 수급에 있어 러시아의 영향을 받아왔으나, 미얀마와 중앙아시아 로부터의 에너지 도입과 함께 이제 중국은 미국산 LNG라는 또다른 카드를 가지게 되었다.

현재 상황이 가장 불리한 국가는 러시아일 것이다. 주로 파이프라인을 통해 동북아시아와 유럽에 가스를 수출하였던 기존의 행태를 벗어나 야말(Yamal) 반 도에서 새로운 LNG 개발을 위해 투자하고 있음에도 불구하고, 러시아가 주요 LNG 수출국으로 거듭나기에는 많은 난관이 있다. 아마도 어쩌면 독일과의 '노 드 스트림 II(NordStream II)'과 터키와의 ‘터키 스트림(TurkStream)' 파이프라인 프로젝트가 유럽 시장을 지키기 위한 가스프롬의 마지막 시도일 수 있다.

현재 상황의 최대 수혜자는 셰일혁명을 주도하고 있는 미국이며, 향후 미 국의 가스 수출량은 크게 증가할 것이다. 2016년 기준 미국의 LNG 수출량은 전세계 16 위 그리고 전체 시장의 $1 \%$ 에 불과하지만, 2020 년경 미국은 세계 LNG 물량의 $20 \%$ 정도를 담당하게 되면서, 각각 $30 \%$ 와 $17 \%$ 의 시장지분을 가지고 있는 카타르와 오스트레일리아와 함께 세계 가스 시장의 주요 공급국 이 될 것이다. 셰일혁명으로 인해 러시아와 같은 전통적인 공급국은 미국이라 는 강력한 경쟁자에 대처하여야 할 것이며, 이러한 경쟁은 과거와 같이 지역 
적 시장을 배경으로 한 것이 아닌 글로벌 시장을 그 배경으로 할 것이다.

미국은 현재 유리한 고지를 점하고 있다. 그렇다면 미국의 전략은 향후 어 떻게 변화할 것인가? 미국의 전략가 피터 지한(Peter Zeihan)이 『돌발적인 초강 대국: 미국의 압도적 우위와 다가오는 혼돈의 세계(The Accidental Superpower:

The Next Generation of American Preeminence and the Coming Global Disorder)』(New York: Twelve, 2014)에서 주장한 것처럼, 앞으로 미국은 강 력한 군사력을 보유하고 있는 상황에서 에너지까지 확보하게 된 이상 굳이 다른 국가들의 문제에 개입하기를 기피하는, 고립주의적이고 “세계 문제에 관심이 없는 세계적인 강대국(a global power without global interests)"으로 변모할 것인가? 경제의 세계화(economic globalization)와 더불어 제 4 차 산업 혁명으로 인해 ‘글로벌 가치사슬’이 재편되고 있는 작금의 상황에서 미국이 다시 제 2 차 세계대전 이전의 미국으로 돌아간다는 것은 불가능하다. 그렇다 면 강력한 경제력과 군사력을 통해 패권을 유지하고 있는 미국이 이제 에너 지라고 하는 또 다른 강력한 '무기’를 보유하게 된 상황이 곧 미국의 패권과 기존 국제질서의 공고화를 의미하는가? ‘자원의 무기화’가 가능한 미국은 이 제 세계 에너지 시장에서 러시아를 패배시키는 것은 물론이고 중국의 추격을 무위로 만들 수 있을 것처럼 보이기도 한다.

하지만 과거 거대 에너지 ‘구매자'에서 이제 거대 에너지 '판매자'로 변모 하게 될 미국의 ‘입장’ 변화가 미국의 전략에 영향을 미치지는 않을까? 에너 지 ‘구매자’로서 미국이 과거에 사용하던 전략과 '힘’을 투사하는 방식이 '판 매자’로 입장이 변화된 이후에도 지속될 수 있을까? 지속된다고 하더라도 과 거와 같은 전략적 이익의 확보가 가능할까? 특히 동북아시아 지역이 세계에 서 가장 거대한 에너지 시장이며 결국 '판매자' 미국에게 주요한 '상권'일 수 밖에 없다는 점을 감안하면, 같은 '구매자' 입장에서 중국과 에너지 확보를 위해 경쟁하며 중국의 에너지 수송 안전을 위협하던 미국은 더 이상 존재하 지 않을 것이다. 즉 미국의 제7함대는 여전히 동북아시아에 강력한 전투력을 가지고 존재하겠지만 그 성격은 변할 수밖에 없을 것이다. 결국 입장의 변화 는 전략의 변화를 가져오며, 장사꾼은 절대로 판을 깨지는 않는 법이다. 